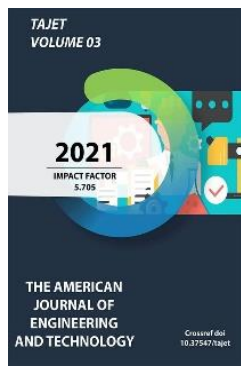

Copyright: Original content from this work may be used under the terms of the creative commons attributes 4.0 licence.

\section{Methods Of Ensuring Occupational Safety And Health In Sports}

\author{
Shovkiddin Narziev \\ PhD, Tashkent State Technical University, Tashkent, Uzbekistan \\ Shohruhbek Latibov \\ PhD Student, Tashkent State Technical University, Tashkent, Uzbekistan
}

\title{
ABSTRACT
}

The article considers the ways of ensuring the safety of athletes and the problems of studying the compliance of an educational institution with the safety standards of a gym, an open sports ground, as well as sports equipment and additional equipment. In addition to studying the causes of injuries among people working in the sports industry, materials on the main areas of their labor protection were analyzed.

\section{KEYWORDS}

Sports, physical culture, occupational safety, injuries, training, sports, organizational, material and technical, medical and biological, psychological, pedagogical.

\section{INTRODUCTION}

In Uzbekistan, the development of the sphere of physical culture and sports is considered at the level of state policy and is used as a guaranteed means of healthy development, education of a generation with physical and mental potential and an important direction of strategic importance in promoting the ideas of national independence [1]. 
Today, it is no secret that significant changes have taken place in our country in the development of this network. For the purpose of competent education of the younger generation, sports complexes that meet the requirements of state standards have been built, and they function effectively. Physical education and sports should be an integral part of the general culture of the country's citizens [2].

Physical fitness is the most important condition for maintaining health, and its improvement depends on the transition of physical education classes in schools to a higher level aimed at improving health[3]. Traditionally organized classes in physical education are aimed at the development of certain physical abilities of schoolchildren, the formation of knowledge and skills characteristic of this age, knowledge that meets the requirements of physical education [4].

It is known that the activity of athletes occurs in most sports, especially in professional and senior sports, in connection with the tension of the basic motor system from the influence of various external and internal forces. Training, training and competitions are aimed at training and demonstrating strong, agile, agile, beautiful and highly athletic equipment. And this, of course, can lead to injuries at the beginning of training camps, at the end and during competitions, due to a lack of mental, physical training, sports skills, in some cases, the athlete suffers from a concussion, resulting in a sharp movement.

\section{LITERATURE ANALYSIS}

Injury to the ligaments in sports training is 8-10 percent of the total number of injuries [2].
Injuries received in physical education classes account for $20 \% \quad[3,5]$. Although we take sports injuries, they are not in the first place in the overall structure of the injuries, but in terms of the weight and proportion of bone fractures, they are in the second place after road traffic injuries $[1,5,6]$.

Therefore, injury of students (especially in physical education and sports training) requires great attention, study and implementation of preventive measures at all stages of Physical Education[6].

Compliance with the protection of sports activities and safety measures are important components of the life and health maintenance factors of students and the successful conduct of physical education training is a must $[7,8]$. Physical education, in contrast to other educational disciplines, requires the presence of traumatic factors and special compliance with safety measures, since it requires a lot of physical activity.

Therefore, in order to reduce the dynamics of injuries and maintain the health of specialists, it is necessary to introduce into practice legal, socio-economic, organizational-technical, sanitary-hygienic, therapeutic-prophylactic, rehabilitation measures [9].

\section{MATERIALS AND METHODS}

One of the most important reserves to reduce the risk of injury is to constantly take into account the age and sex characteristics of athletes, their physical and technical training

By creating and applying innovative solutions aimed at preventing and mitigating the consequences of sports injuries, the 
establishment and implementation of rules on sports activities, the requirements for the organization of training, the sanitary and hygienic requirements that determine the microclimate and weather conditions of sports facilities, the technical requirements for sports facilities and equipment, the requirements of the legal-normative documents of labor protection

In most sports, for example, in athletics and wrestling sports - legs (66\%), in boxers - head and face (65\%), in basketball and volleyball players - Palm paws (80\%), in tennis players and young gymnasts - elbow joint(70\%), in players - knee joint (48\%) There is a probability of injury (see fig. 1). Although the severity or severity of sports injuries depends on the type of sport, mild injuries are more common in threeraydi (90\%).

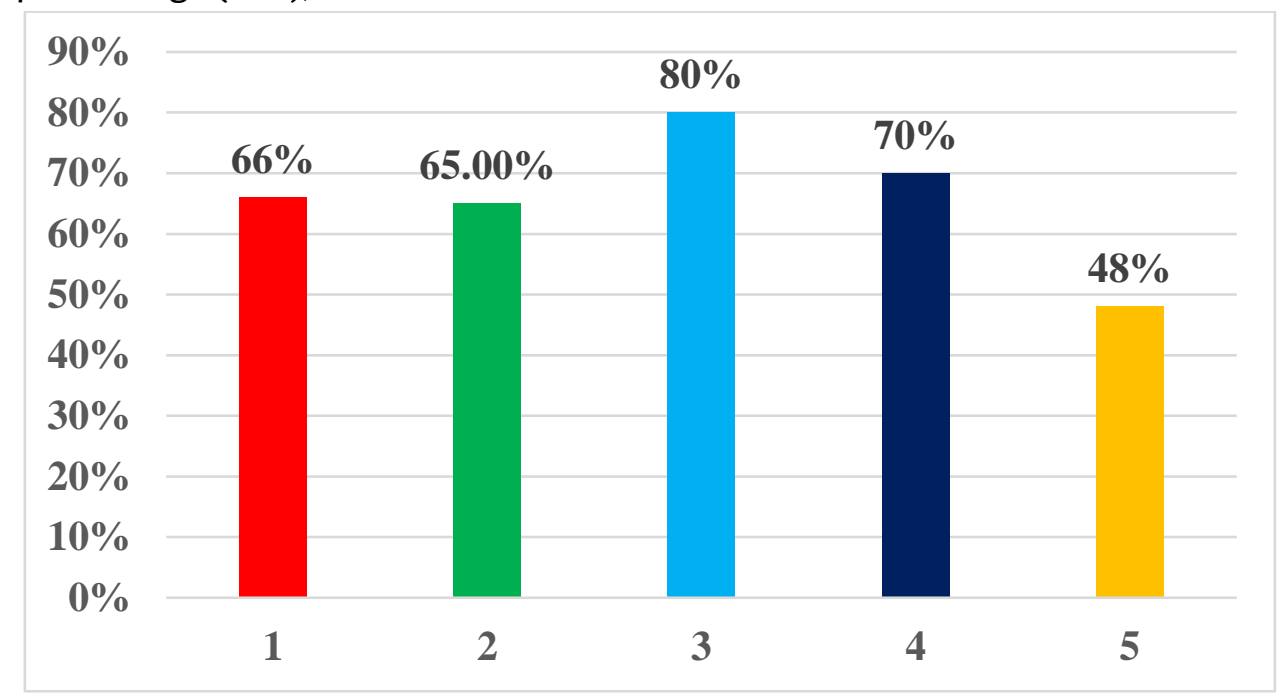

1-wrestling (legs); 2-boxing (face part); 3-basketball (palm part); 4-tennis (elbow joint); 5footballplayers (knee joint).

Figure 1. Indications for injury of the human body in sports

The physical education teacher (teacher) or the person conducting the lesson during extracurricular work is directly responsible for protecting the life and health of students and is obliged to:::

- Carefully inspect the place before the start of classes to make sure that the simulators work well, make sure that the installed equipment is
- Sealed, study the sanitary and hygienic conditions of the hall;

- Teach students safety techniques when performing physical exercises, monitor compliance with safety rules during training;

- Each participant should pay special attention to the results of the medical examination, their mental and mental preparation, if necessary, it will be 
necessary to refer them to a doctor for examination.

The most optimal ratio of youth involvement in sports, their proper development is that at least $75 \%$ of children participate in primary training groups, $23 \%$-in training groups, about
$1.5 \%$ - in sports improvement groups, $0.50 \%$ - in training in high - level sports skill groups (see Fig. 2). In fact, no more than $35-40 \%$ of respondents will participate in primary training groups, and the main contingent (about 60\%) in training groups.

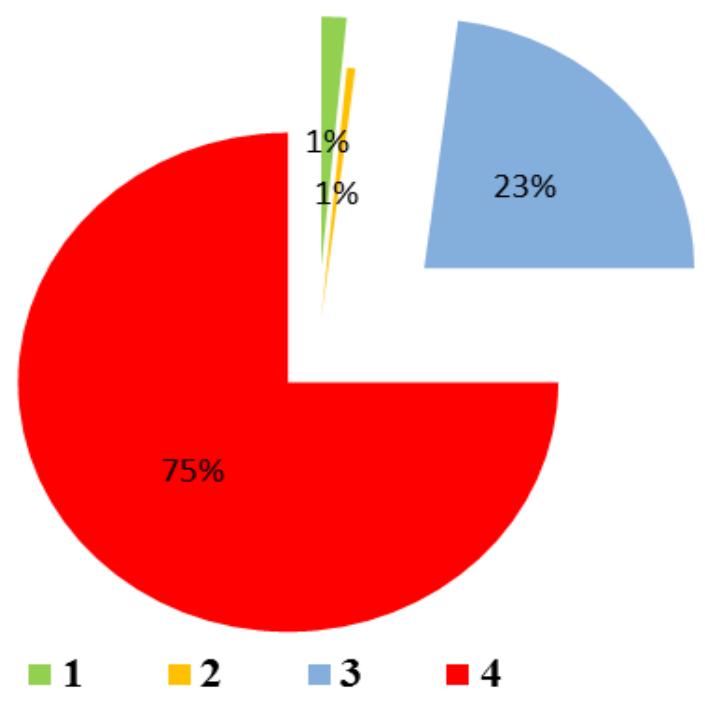

1-in the initial preparatory groups; 2 -in the training groups;

3 -in sports improvement groups; 4-in high Sports skill groups.

Figure 2. Groups of participation in sports activities.

Athletes injury prevention involves several organizational, material-technical, biomedical, psychological, sports and pedagogical areas. Each of them provides great opportunities for risk factors, prevention of sports injuries, rapid and effective treatment of sports injuries, recovery after them and increase the effectiveness of sports training. Risk factors for sports injuries are usually divided into two types: external and internal factors [11]. External factors these are the time of the weather season, the time of day, the sanitary and hygienic condition of the sports field, if the sports outfit (special shoes) enters, then the level of readiness for internal factors is divided into previous sports, flexibility, strength, elasticity, stagnation of joints, biomechanics, mental (psycho-social factors).

Improving labor protection in sport it is important to rely on the surface part of the sports grounds, to be able to choose the sports clothes of the athlete. The reason is that sportswear should be suitable for sports activities, sports shoes should fit on the Sports Ground, which will prevent premature injury.

A more serious factor in danger lies in the size of the external forces that occur due to the anatomical features of this athlete, the technique of movements, the design of sports shoes. The design of sports shoes helps to correct the structure of movements, eliminate the negative impact of the geometric structure 
of the skelet and reduce the likelihood of injury, [5] improve the effectiveness in training.

High air temperature, especially high humidity, can cause various kinds of heat damage. The probability of thermal damage depends on various external factors (temperature and humidity, air movement speed, sunlight) and the behavior of the athlete (optimal microclimate maintenance, strong fatigue, dehydration of the body and inappropriate clothing).

Equipment on sports grounds should be made of harmless materials that do not harm the health of athletes, and also correspond to their height and age.[3]

\section{CONCLUSIONS}

1. Safety measures for physical education training participants are introduced before the start of classes.

2. Safety regulations are aimed at minimizing injuries during training and are mandatory for all participants of the training process.

3. Each aspect of the training of athletes is characterized by a level of perfection, that is, the injury of the athlete, desensitization, casalanmasyn with subsequent labor protection

4. Compliance with the rules and requirements for the protection of sports facilities and labor equipment is accepted by evaziga at a meeting of athletes and employees.

\section{REFERENCES}

1. Sulaymonovich S. S. et al. Methods of Forecasting and Occurrence of Traumatic Damages i Sport
//International Journal of Innovative Technology and Exploring Engineering. - 2019. - T. 8. - №. 9 S2. pp. 223-225.

2. Sulaymonovich, S. S., \& Murtozayevich, N. S. (2020). Studying and accounting sports injuries. ACADEMICIA: An International Multidisciplinary Research Journal, 10(7), 759-763.

3. Platonov V. N. The system of training athletes in Olympic sports. General theory and its practical applicationsMoscow: Sovetsky Sport, 2005.

4. Нарзиев, Ш. М., \& Рахимова, А. Х. К. (2021). ПРИМЕНЕНИЕ И АНАЛИЗ ПЕДАГОГИЧЕСКИХ МЕТОДОВ В УЧЕБНОМ ПРОЦЕССЕ. ТЕСНика, (1 (5)).

5. Lindsay D. et al. Principles and methods of rehabilitation / / Sports medicine. - K.: Olympic literature, 2003. - 298-314 p.

6. Shovkiddin N. et al. Provision Of Labor Protection And Analysis Of Injuries of Active Participants //Journal of Contemporary Issues in Business and Government. - 2021. - T. 27. - №. 2. pp. 1902-1909.

7. Нарзиев, Ш. М., \& Ботиров, А. Б. (2021). БЕЗОПАСНОСТЬ ДЕЯТЕЛЬНОСТИ ЧЕЛОВЕКА МЕТОДЫ ИЗУЧЕНИЯ И АНАЛИЗА РИСКОВ В ТРУДОВОМ ПРОЦЕССЕ. ТЕСНика, (1 (5)).

8. Sulaimanovich S. S., Murtozaevich H. S. Causes and Prevention of Athlete Injuries During Training Sessions and Competitions //JournalNX. - pp. 325329. 
9. Narziev, S., Shokirov, P., Rakhmonov, N., Valieva, Z., \& Saidova, S. (2020). Theoretical analysis of the causes of injury in sports activities and their reduction measures. Journal of Advanced Research in Dynamical and Control Systems, 12(S2), 166-170.

10. Shovqiddin N. et al. Prevention of Sport Injuries //Solid State Technology. - 2020. - T. 63. - №. 6. - pp. 1186811875.

11. Shovkiddin, N., Eleonora, Y., Surayo, A., Nargiza, K., \& Saodat, N. (2020). PROBLEMS OF ENSURING THE SAFETY OF SPORTS ACTIVITIES AND REDUCING INJURIES. Journal of Critical Reviews, 7(11), 428-432. 